\title{
Persepsi Perawat Pelaksana Tentang Budaya Organisasi
}

\author{
Mila Triana Sari \\ Departement of Nursing, Baiturrahim School of Health Science \\ email: milatrianasari273@yahoo.com
}

\begin{abstract}
Every organization has a culture that is an important factor to determine the success of the organization in achieving its objectives. Organizational culture is a shared value that is owned and reflected in the behavior of members of the organization. Organizational culture has a strong influence throughout the hospital, besides being an identity, it is also a reference or guideline for nurse behavior. This study aims to determine the nurse practitioners perception on organizational culture in the Inpatient Installation of the Mental Hospital of the Jambi Province. This research began from March to September 2018. The research method is descriptive analytics. The population of this study was 106 Nurses, with a sample involving 86 nurses. Data collection the instrument used was the modified instrument of organizational culture by Denison. The results of the study, a total of $77.9 \%$ of nurses perceiving the organizational culture good. Suggestions for hospital management are the need to socialize organizational culture for each element, need to maintain with evaluating each its component.
\end{abstract}

Keyword:

Organizational culture, nurse practitioners

\section{PENDAHULUAN}

Rumah sakit sebagai organisasi pemberi pelayanan kesehatan memiliki karakteristik yang membedakannya dengan organisasi lain, karakteristik inilah yang mendasari terbentuknya budaya organisasi (Ardana,2009). Robbins (2006) mendefenisikan budaya organisasi sebagai sitem nilai yang dianut oleh anggota organisasi yang membedakan dengan organisasi itu dengan organisasi lainnya. Sistem nilai yang diyakini bersama merupakan karakteristik organisasi yang digunakan sebagai acuan dan pedoman dalam bekerja bagi anggota organisasi. Budaya organisasi berfungsi sebagai pengikat seluruh komponen organisasi, terutama pada saat organisasi mengalami guncangan baik dari dalam maupun luar akibat adanya perubahan dan sebagai suntikan energi untuk mencapai kinerja yang tinggi. Selain itu budaya organisasi juga sebagai pemandu dalam membentuk sikap serta perilaku karyawan dan mempermudah timbulnya komitmen. Budaya organisasi sangat penting untuk mendorong kinerja karyawan yang produktif (Robbins, 2006).

Rumah Sakit Jiwa memiliki budaya organisasi yang berbeda dengan Rumah Sakit Umum karena Rumah Sakit Jiwa melayani dan memberikan asuhan terhadap pasien-pasien yang mengalami gangguan kejiwaan. Visi yang ingin dicapai Rumah Sakit Jiwa Daerah Jambi dalam pembangunan kesehatan tahun 20162021 adalah menjadi Rumah Sakit Jiwa hebat dengan pelayanan prima. Sedangkan budaya kerja yang di anut Rumah Sakit Jiwa Daerah Jambi Pelayanan dengan penuh BAKTI (Berwibawa, Adil, Kerjasama, Tanggungjawab, Itikad Baik). Adanya motto dan budaya kerja dapat membantu menanamkan mental kerja yang baik bagi efektifitas dan efesiensi organisasi Rumah Sakit Jiwa Daerah Jambi Profil RSJD, 2017). Budaya organisasi yang ada di Rumah Sakit Jiwa Daerah Jambi perlu dilakukan evaluasi, untuk mengetahui efektifitasnya.Menurut Ardana (2009) salah satu faktor untuk meningkatkan efektifitas organisasi berasal dari budaya organisasi.

Hasil penelitian Iqbal dan Agritubella (2017) didapatkan bahwa terdapat hubungan budaya organisasi dengan kinerja perawat, perawat akan bekerja dengan baik apabila didukung budaya organisasi yang baik khususnya penyesuaian. Penyesuaian adalah kemampuan perawat untuk dapat beradaptasi dengan nilai-nilai dan aturan organisasi.

Budaya organisasi rumah sakit merupakan pedoman atau acuan untuk mengendalikan prilaku organisasi dan prilaku perawat, serta team kesehatan lain dalam berinteraksi untuk mencapai tujuan organisasi, ini sesuai dengan penelitian Darajat dan Rosyidah (2012) yang menyatakan budaya organisasi dapat meningkatkan komitmen organisasi. Budaya organisasi yang dipersepsikan baik juga berkinerja baik (Panjaitan,2014).

Berdasarkan wawancara pendahuluan dengan 10 perawat pelaksana, masih ada perawat pelaksana yang belum memahami visi dan misi rumah sakit, masih ada perawat yang datang tidak tepat waktu, sehingga saat overan dinas tidak lengkap, sebagian perawat dilibatkan untuk pengambilan keputusan yang berkaitan dengan pelayanan diruangan. Penelitian ini bertujun untuk mengetahui persepsi perawat pelaksana tentang budaya organisasi di Instalasi Rawat Inap Rumah Sakit Jiwa Jambi 


\section{METODE PENELITIAN}

Penelitian ini merupakan penelitian deskriptif analitik, yang bertujuan untuk mengetahui persepsi perawat pelaksana tentang budaya organisasi di Instalasi Rawat Inap Rumah Sakit Jiwa Jambi. Populasi penelitian ini adalah 106 perawat pelaksana. Besarnya sampel adalah 86 perawat pelaksana yang diambil dengan teknik total sampling, dengan criteria inklusi tidak sedang menjabat, tidak sedang cuti, tugas belajar atau sakit. Penelitian dilakukan pada bulan September 2018 pada 16 instalasi rawat inap RSJ Jambi. Alat pengumpul data yang digunakan terdiri dari dua bagian. Bagian satu terkait karakteristik perawat pelaksana berdasarkan teori Robbins (2006) dan bagian kedua untuk menilai persepsi tentang budaya organisasi berdasarkan teori Denison yang terdiri dari unsur keterlibatan, penyesuaian, konsistensi dan Misi, berjumlah 32 item. Hasil uji coba instrument budaya organisasi bernilai $r$ rentang antara 0.750 sampai dengan 0.882 ( $r$ tabel $=0.632$ ) dan nilai alpha 0.971 Penelitian ini dianalisis secara univariat.

\section{HASIL DAN PEMBAHASAN}

Hasil penelitian ini ditampilkan dalam bentuk tabel distribusi frekuensi. Karakteristik perawat pelaksana pada tabel 1 dan persepsi perawat pelaksana tentang budaya organisasi pada tabel 2 dan tabel 3 , selanjutnya dapat dilihat pada tabel-tabel dibawah ini:

Tabel 1. Karakteristik Perawat Pelaksana di Instalasi Rawat Inap Rumah Sakit Jiwa Jambi Tahun $2018(n=86)$

\begin{tabular}{|c|c|c|c|}
\hline \multirow[t]{2}{*}{ No } & \multirow[t]{2}{*}{ Variabel } & \multicolumn{2}{|c|}{ Frekuensi } \\
\hline & & $\mathbf{n}$ & $\%$ \\
\hline \multirow[t]{4}{*}{1.} & Usia Perawat pelaksana & & \\
\hline & 1. Dewasa Awal (26-35) & 46 & 53.5 \\
\hline & 2. Dewasa Akhir (36-45) & 25 & 29.0 \\
\hline & 3. Lansia Awal (46-55) & 15 & 17.5 \\
\hline \multirow{3}{*}{2.} & Pendidikan & & \\
\hline & 1. DIIIKeperawatan & 61 & 71.0 \\
\hline & 2. Ners & 25 & 29.0 \\
\hline \multirow[t]{3}{*}{3.} & Jenis Kelamin & & \\
\hline & 1. Laki-laki & 32 & 37.2 \\
\hline & 2. Perempuan & 54 & 62.8 \\
\hline \multirow[t]{3}{*}{4.} & Lama Bekerja & & \\
\hline & 1. $<5$ Tahun & 34 & 39.6 \\
\hline & 2. >5 Tahun & 52 & 60.4 \\
\hline \multirow[t]{3}{*}{5.} & Status Pernikahan & & \\
\hline & 1. Menikah & 50 & 58.1 \\
\hline & 2. Belum Menikah & 36 & 41.9 \\
\hline \multirow[t]{3}{*}{6.} & Status Kepegawaian & & \\
\hline & 1. PNS & 56 & 65.1 \\
\hline & 2. Non PNS & 30 & 34.9 \\
\hline
\end{tabular}

Tabel 1 menggambarkan bahwa lebih dari setengah $(53.5 \%)$ perawat pelaksana di instalasi RSJ Jambi berusia 26-35 tahun, ini merupakan usia produktif, sehingga akan lebih mampu dan mudah dalam beradaptasi dan memahami budaya organisasi di RSJ, Menurut Levinston (1994, dalam Susana, 2003), yang menyatakan bahwa usia antara 22-30 tahun merupakan tahap usia memasuki usia dewasa, dimana umumnya pada masa ini seseorang memulai komitmen untuk masa depan dan merupakan fase pekerjaan yang ditandai dengan pencarian identitas dan pencapaian tujuan karir yang memuaskan.

Selain itu, menurut Hasibuan (2003) umur akan mempengaruhi kondisi fisik, mental, kemampuan kerja dan tanggung jawab seseorang. Karyawan yang umurnya lebih tua kondisi fisiknya kurang, tetapi bekerja ulet, mempunyai kedewasaan teknis dan psikologis serta bertanggung jawab besar. Peneliti berpendapat perawat yang berusia dewasa dan produktif lebih memiliki kompetensi, ketrampilan dan kematangan dalam memberikan pelayanan keperawatan, serta mempunyai komitmen yang tinggi terhadap mutu pelayanan yang diberikan. Hal ini menjadi modal dasar bagi rumah sakit untuk meningkatkan kualitas mutu pelayanan keperawatan di rumah sakit melalui kegiatan pendidikan lanjut dan pelatihan bagi perawat pelaksana

Sebagian besar perawat pelaksana berpendidikan DIII Keperawatan. Tingkat pendidikan dapat meningkatkan kemampuan perawat dari segi intelektual, teknikal dan interpersonal yang dibutuhkan dalam memberikan asuhan keperawatan. Hal ini sesuai dengan pendapat Likert (1967) dikutip Gibson (1996) bahwa tingkat pendidikan yang tinggi pada umumnya menyebabkan orang akan mampu dan bersedia menerima posisi dan bertanggung jawab terhadap tugas yang diberikan. Pendapat Siagian (2006) memperkuat bahwa semakin tinggi pendidikan seseorang maka semakin besar keinginan memanfaatkan pengetahuan dan keterampilannya. Sebagian besar perawat pelaksana yang menjadi responden pada penelitian ini, adalah perempuan $(62,8 \%)$, secara proporsional perempuan memiliki kinerja dan ketelitian yang lebih baik (Rusdi,2001). Sebagian besar lama bekerja perawat pelaksana $>5$ tahun $(60.4 \%)$, Dessler (1997, dalam Pandawa, 2006) menjelaskan lamanya waktu seseorang dalam menentukan pilihan pekerjaan yang cocok adalah 5 tahun. Hasil penelitian ini tidak sesuai dengan pendapat Hersey \& Blanchard (1993) bahwa pengalaman kerja yang diperoleh seseorang sangat mempengaruhi kemampuannya dan diasumsikan bahwa semakin lama seseorang bekerja, maka akan semakin baik kemampuannya. Lama bekerja akan membuat pengalaman lebih baik dan sudah beradaptasi dengan budaya organisasi di lingkungan pekerjaannya sesuai dengan penelitian (Rudianti,Handiyani,Sabri, 2013). Terkait dengan status pernikahan lebih dari setengah sudah menikah $(58,1 \%)$. Status kepegawaian perawat pelaksana sebagian besar merupakan pegawai negeri sipil (PNS) sebesar 
(65,1\%), hasil ini menggambarkan bahwa dengan status PNS diharapkan penyesuaian dan konsistensi terhadap budaya organisasi dilingkungan RSJ dapat lebih ditingkatkan.

\begin{tabular}{|c|c|c|c|}
\hline \multirow[t]{2}{*}{ No } & \multirow[t]{2}{*}{ Komponen } & \multicolumn{2}{|c|}{ Frekuensi } \\
\hline & & $\mathbf{n}$ & $\%$ \\
\hline 1. & $\begin{array}{l}\text { Keterlibatan } \\
\text { a. Kurang } \\
\text { b. Baik }\end{array}$ & $\begin{array}{l}20 \\
66\end{array}$ & $\begin{array}{l}23.3 \\
76.7\end{array}$ \\
\hline 2. & $\begin{array}{l}\text { Penyesuaian } \\
\text { a.Kurang } \\
\text { b.Baik }\end{array}$ & $\begin{array}{l}23 \\
63\end{array}$ & $\begin{array}{l}26.7 \\
73.3\end{array}$ \\
\hline 3. & $\begin{array}{l}\text { Konsistensi } \\
\text { a.Kurang } \\
\text { b.Baik }\end{array}$ & $\begin{array}{l}17 \\
69\end{array}$ & $\begin{array}{l}19.8 \\
80.2\end{array}$ \\
\hline 4. & $\begin{array}{l}\text { Misi } \\
\text { a.Kurang } \\
\text { b. Baik }\end{array}$ & $\begin{array}{l}15 \\
71\end{array}$ & $\begin{array}{l}17.4 \\
82.6\end{array}$ \\
\hline
\end{tabular}

Tabel 3. Persepsi Budaya Organisasi pada Perawat

Pelaksana di Instalasi Rawat Inap Rumah Sakit Jiwa Jambi Tahun $2018(n=86)$

\begin{tabular}{|c|c|c|}
\hline \multirow[t]{2}{*}{ Persepsi Budaya Organisasi } & \multicolumn{2}{|c|}{ Frekuensi } \\
\hline & $\mathbf{n}$ & $\%$ \\
\hline a. Kurang Baik & 19 & 22.1 \\
\hline b. Baik & 67 & 77.9 \\
\hline
\end{tabular}

Berdasarkan pada tabel 2 dan tabel 3 di atas, persepsi perawat pelaksana tentang budaya organisasi berdasarkan komponen budaya organisasi adalah sebagian besar mempersepsikan keterlibatan baik (76.7\%), mempersepsikan penyesuaian baik (73.3\%), mempersepsikan konsistensi baik (80.2\%) dan mempersepsikan misi baik. (82.6\%). Secara komposit sebagian besar atau mayoritas perawat pelaksana di RSJ Jambi berpersepsi baik tentang budaya organisasinya(77.9\%). Hasil penelitian ini sesuai dengan penelitian Kholifah (2013) dan RU Panjaitan (2014), yang menyampaikan hasil penelitiannya persepsi budaya organisasi yang baik oleh perawat pelaksana di RSUD Ambarawa dan RS Bogor akan menunjukkan kinerja yang baik sesuai dengan tujuan organisasi dan tercermin pada nilai-nilai yang diterapkan saat pemberian asuhan keperawatan pada pasien.

Berdasarkan hasil penelitian, untuk komponen keterlibatan adalah kunci untuk diperhatikan dalam mengimplementasikan budaya organisasi. Keterlibatan adalah faktor kunci dalam budaya organisasi, yang merupakan karakteristik nilai dari organisasi yang menempatkan pandangan tentang pentingnya keterlibatan seluruh pegawai yang bekerjasama dalam mencapai tujuan organisasi (Tika, 2006). Berdasarkan hasil analisis univariat didapatkan sebagian besar persepsi perawat pelaksana tentang keterlibatan adalah baik (76.7\%). Hasil penelitian ini sesuai dengan pendapat Tika (2006) bahwa keterlibatan yang tinggi dari anggota organisasi berpengaruh terhadap kinerja perusahaan dalam hal ini RSJ Jambi.

Denison (1990) menjelaskan keterlibatan yang tinggi akan menekan kapasitas organisasi pada fleksibilitas dan perubahan yang merupakan consensus sebagai anggota organisasi untuk melibatkan diri dalam setiap kegiatan organisasi. Selain itu Walton dan Lawler dalam Tika (2006) mengemukakan bahwa keterlibatan merupakan strategi manajemen bagi kinerja perusahaan efektif dan strategi karyawan untuk lingkungan kerja yang baik. Asumsi peneliti keterlibatan yang tinggi dari perawat pelaksana dalam melakukan kerjasama dalam tim di organisasi akan berdampak pada peningkat kinerja organisasi. Kondisi ini perlu disadari oleh manajer keperawatan untuk terus berupaya memberikan kesempatan kepada perawat pelaksana terlibat dalam kegiatan di rumah sakit.

Hasil penelitian didapatkan sebagian besar persepsi perawat pelaksana tentang penyesuaian adalah baik (73.3 \%). Penyesuaian dalam penelitian ini adalah penilaian perawat pelaksana terhadap nilai-nilai rumah sakit yang mendukung organisasi dalam menerima perubahan lingkungan, fokus pelayanan dan pembelajaran organisasi. Penyesuaian merupakan kebutuhan organisasi dalam melaksanakan kegiatan dalam lingkungan organisasi tersebut, dimana organisasi memegang nilai dan kepercayaan yang mendukung kapabilitas dalam menerima, menginterpretasikan dan menterjemahkan tanda-tanda dari lingkungan kedalam perubahan prilaku internal dari organisasi. Tiga asfek dari kemampuan adaptasi ini yaitu fokus pada pelanggan, menciptakan perubahan dan pembelajaran organisasi (Denison, 2000). Menurut Marquis dan Hoston (2000) menjelaskan unit dari organisasi mempunyai budaya, penyesuaian akan terjadi bila budaya unit sejalan dengan budaya organisasi dan budaya keperawatan sejalan dengan budaya profesional lain.

Penelitian ini juga menemukan sebagian besar persepsi perawat pelaksana tentang konsistensi adalah baik (80,2\%). Konsistensi adalah nilai dan sistem yang mendasari kekuatan suatu budaya. Nilai ini memfokuskan pada integrasi sumber-sumber organisasi, koordinasi dan sistem kontrol dan konsistensi organisasi dalam mengembangkan sistem yang efektif dalam melaksanakan kegiatan organisasi. Karakteristik konsistensi meliputi koordinasi, integrasi, kesepakatan dan nilai-nilai inti (Tika, 2006). Menurut Seashare (1945, dalam Tika, 2006) mengemukakan bahwa tingkat konsistensi dan integrasi yang tinggi dalam mendukung norma kinerja merupakan prediktor yang baik untuk tingkat efektivitas yang tinggi dan memberi kontribusi terhadap kinerja. 
Hasil penelitian juga menunjukkan sebagian besar persepsi perawat pelaksana tentang misi adalah baik (82.6\%). Menurut Denison (2000) menjelaskan misi memberikan pengaruh besar pada fungsi perusahaan secara internal dan eksternal yang memberi kontribusi pada komitmen jangka pendek dan panjang serta menimbulkan kinerja organisasi yang efektif.

Berdasarkan hasil penelitian dan beberapa pendapat diatas, dari keempat komponen budaya organisasi (keterlibatan, penyesuaian, konsistensi dan misi) sebagian besar dipersepsikan baik (77.9\%) oleh perawat pelaksana, artinya budaya organisasi yang terdiri dari empat komponen tersebut sudah melekat kuat pada perawat pelaksana di RSJ Jambi. Hal ini tentunya perlu menjadi perhatian untuk lebih ditingkatkan. Menurut Atmosuprapto (2001) budaya yang kuat akan berdampak pada citra, kebanggaan, produktivitas dan kinerja organisasi. Lebih lanjut Kotler dan Heskett (1992, dalam Tika, 2006) menyatakan bahwa budaya yang kuat berkaitan dengan kinerja yang unggul, karena memberikan struktur dan control yang dibutuhkan dan meningkatkan komitmen, loyalitas, motivasi, dan inovasi yang memberikan korelasi positif terhadap kinerja.

Budaya organisasi mempunyai peran penting dalam mempengaruhi setiap anggota organisasi saat menjalankan aktifitas serta dapat dibedakan melalui sistem nilai yang di anut oleh anggota organisasi (Robbins, 2006). Menurut Asri (2011) budaya organisasi sebagai suatu pola dari asumsi-asumsi dasar yang ditemukan, diciptakan, atau dikembangkan oleh suatu kelompok tertentu dengan maksud agar organisasi belajar mengatasi atau menanggulangi masalah - masalah yang timbul akibat adaptasi eksternal dan integrasi internal yang sudah berjalan dengan cukup baik.

Salah satu upaya untuk mempertahankan budaya organisasi perawat pelaksana yang baik dirumah Sakit Jiwa Jambi dengan mengkaitkan pemahaman kepada perawat pelaksana khususnya pada komponen budaya organisasi (Keterlibatan, penyesuaian, konsistensi dan misi) dalam menyelesaikan masalah yang ditemui didalam rutinitas keperawatan yang ada diRumah Sakit Jiwa Jambi. Selain itu perlunya managemen RSJ Jambi mensurvey seluruh karyawan termasuk perawat pelaksana untuk memberikan penilaian terhadap budaya organisasi dan budaya kerja yang sudah berjalan selama ini di RSJ Jambi. Hal ini sebagai salah satu bentuk keterlibatan sekaligus memberikan reward terhadap perawat.

Budaya organisasi merupakan persepsi perawat pelaksana tentang hal-hal yang mereka rasakan dan lakukan. Budaya organisasi yang baik menjadikan perawat pelaksana mempunyai semangat yang tinggi untuk memberikan pelayanan yang terbaik bagi pasien sehingga pasien merasa puas dengan pelayanan yang diberikan (Robbin, 2006). Seseorang yang memiliki budaya organiasi dalam dirinya jika ditunjang dengan kompensasi dan budaya dalam bekerja yang baik akan dapat meningkatkan kinerjanya dalam mengaplikasikan asuhan keperawatan menjadi lebih optimal. Dalam hal ini disarankan juga agar menggali lebih dalam budaya organisasi perawat pelaksana dalam mendukung emosional agar dapat memperoleh budaya organisasi lebih baik dalam berkerja. Hal lain yang menjadi hak perawat juga perlu ditunaikan seperti kesempatan untuk meningkatkan pendidikan formal maupun informal, pengembangan kompetensi, penghargaan yang sesuai, dan melaksanakan metode penugasan di ruangan dengan konsisten dan sesuai kaidah. Managemen rumah sakit perlu mengevaluasi, serta mempertahankan program dalam mengembangkan budaya organisasi yang sudah baik yang ada diruang rawat inap Rumah Sakit Jiwa Daerah Provinsi Jambi.

\section{SIMPULAN}

Berdasarkan hasil penelitian yang dilakukan pada 86 perawat pelaksana di Rumah Sakit Jiwa Daerah Provinsi Jambi Tahun 2018 maka didapat kesimpulan bahwa sebagian besar (77.9\%) perawat pelaksana memiliki budaya organisasi yang baik. Budaya organisasi yang sudah baik perlu terus dipertahankan dengan mengevaluasi setiap komponennya dengan melibatkan dan memperhatikan aspirasi perawat sehingga perawat merasa dihargai keberadaannya.

Perlu dilakukan penelitian kualitatif untuk menggali lebih dalam terkait budaya organisasi di RSJ Jambi.

\section{DAFTAR PUSTAKA}

Andriani, M., Sahar, J., Huriani, E. (2012).

Hubungan budaya organisasi dan karakteristik perawat dengan perawat pelaksana di ruang rawat inap RSUD Dr. Achmad Mochtar Bukittinggi tahun 2012. http://repository.unand.ac.id/19905/BAB1. pdf

Ardana, Komang dkk. (2009). Perilaku Keorganisasian. Graha Ilmu. Yogyakarta.

Asri, L. (2011). Budaya Organisasi. Graha IImu. Yogyakarta.

Bateman, Thomas S., Snell Scott A., (2008), Manajemen : Kepemimpinan dan Kolaborasi dalam Dunia yang Kompetitif. Salemba Empat. Jakarta.

Darajat, L.N dan Rosyidah. (2011). Hubungan Budaya Organisasi dengan Komitmen Organisasi Perawat Bagian Rawat Inap Kelas II dan III Runah Sakit PKU 
Muhammadiyah Yogyakarta. Jurnal Kesmas ISSN:1978-0575.

Depkes, RI. (2009). Profil Kesehatan Indonesia. Departemen Kesehatan RI. Jakarta.

Denison. D. R. (2000). Organitational Culture Introduction. Philadelpia. Mosby Company.

Gibson, J.L., Ivancevich, J.M., Donelly, J.H. (1996). Organisasi: perilaku, struktur, proses. Edisi kelima. (Soekrisno. A, Penerjemah). Jakarta: Erlangga

Grace. (2012). Organisasi dan Manajemen. EGC. Jakarta.

Hasibuan, MS.P (2001), Manajemen Sumber Daya Manusia, edisi revisi , PT Bumi Aksara, Jakarta.

Hidayat, A.A. (2009). Metode Penelitian Keperawatan dan Teknik Analisis Data. Salemba Medika. Jakarta.

llyas, Y. (2002). Kinerja. Teori, Penilaian, dan Penelitian. Cetakan ketiga. Jakarta.

Iqbal, M dan Agritubella, S.M. (2017). Hubungan Budaya Organisasi dengan Kinerja Perawat Pelaksana di Rawat Inap RS $P M C$. Jurnal Endurence 2(3) 283-293.

Kemenkes RI. (2017). Infodatin Situasi Keperawatan Indonesia. Jakarta: Pusat Data dan Informasi Kementrian Kesehatan RI.

S.Kholifah. (2013) Hubungan penerapan budaya Organisasi dengan kepuasan pasien di RSUD

Ambarawa.https://jurnal.Unimus.ac.id/inde x.php/JMK volume 1, no 1 mei 2013, hal 7-14

Notoatmodjo. (2012). Metode Penelitian Kesehatan. Rineka Cipta. Jakarta.

Panjaitan, et al, Persepsi Perawat Pelaksana tentang Budaya Organisasi dan Kinerja. Jurnal Keperawatan Indonesia Volume 17, No 1, maret 2014, hal 30-38

Panbundu, M.T. 2012. Budaya Organisasi dan Peningkatan Kinerja Perusahaan. Bumi Aksara. Jakarta.

Profil RSJ Jambi. 2017

Robbins, S.P. (2006). Perilaku Organisasi. Jilid I. Alih bahasa oleh tim indeks, Jakarta: PT. Indeks Kelompok Gramedia.

Robbins, S.P. dan Coulter, Mary. 2010. Manajemen Edisi Kesepuluh. Erlangga. Jakarta.

Rudianti Y., Haniyani, H., \& Sabri, L. (2013). Peningkatan kinerja perawat pelaksana melalui komunikasi organisasi di ruang rawat inap rumah sakit. Jurnal Keperawatan Indonesia 16(1), 25-32

Sembiring, Masana. (2012). Budaya dan Kinerja Organisasi. Fokusmedia. Bandung.

Siswadi, Edi. (2012). Birokrasi Masa Depan. Mutiara Press. Bandung.

Sopiah. (2008). Perilaku Organisasi. Andi Offset. Jakarta.
Susana,A (2003). Faktor-faktor yang berhubungan dengan budaya kerja di Ruang Inap RS Immanuel Bandung (tesis magister, tidak dipublikasikan) FIK-UI, Depok Jawa Barat.

Thoha, M. (2016). Perilaku Organisasi Konsep Dasar dan Aplikasinya. Rajawali Pers. Jakarta.

Tinambunan DS. (2016). Pengaruh Budaya Organisasi terhadap Kinerja Perawat di Instalasi Rawat Inap Rumah Sakit Umum Daerah Arifin Achmad Kota Pekan Baru Tahun 2016. Skripsi. Fakultas Kesehatan Masyarakat Universitas Sumatera Utara Medan.

Uha, Ismail Nawawi.(2013). Budaya Organisasi, Kepemimpinan dan Kinerja. Kencana Jakarta. 